\title{
It was Party Identification all along: Question Order Effects on Reports of Party Identification in Britain
}

\author{
ANTHONY HEATH* \\ Nuffield College, Oxford OX1 1NF, England
}

RoY PIERCE

The University of Michigan

\begin{abstract}
The British voter is less likely than the American to make a distinction between his current electoral choice and a more general partisan disposition. This article investigates whether this difference might be due to a methodological difference between the British and American Election surveys: the British surveys, unlike the American, have placed the party identification question after the question on electoral choice, and this order may encourage the British respondents to bring their reports of their party identification into line with their actual votes. A split-sample panel study experiment was conducted to test this hypothesis. The results were not decisive, but they did suggest that the 'improper' question order elicited a smaller proportion of 'true' party identifiers and produced response uncertainty in the reporting of party identification.
\end{abstract}

The concept of party identification is routinely employed in the analysis of British electoral behaviour, but it carries with it the aura of original sin that it acquired when Butler and Stokes (1969) first investigated the phenomenon in the British political context but preferred to label it 'partisan self-image' rather than call it by the familiar name used in the United States.

Butler and Stokes acknowledged that partisan self-images in Britain displayed many of the properties associated with party identification in the United States. The strength of partisan self-image intensified with age; partisan self-images were more

Prepared for delivery at the 1991 Annual Meeting of the American Political Science Association, The Washington Hilton, 29 August to 1 September 1991. Copyright by the American Political Science Association.

* The 1983-1987 British Election Panel Study on which this paper rests was funded by the Sainsbury Family Clraritable Trusts, Perganun Press, and tie ESRC (grail A00250005) and was directed by Anthony Heath, Roger Jowell (Social and Community Planning Research), John Curtice (University of Strathclyde) and Julia Field (Social and Community Planning Research). We are very grateful to the funders, and to the co-directors of the study. 
stable than partisan electoral choices across time; and partisan self-images were associated with the 'homing tendency' displayed in the United States by voters who defect at election time from their standing party identifications. But partisan selfimages in Britain appeared to differ from party identifications in the United States in two ways:

1. Across roughly equivalent electoral intervals, US voters were some four times more likely than British voters to change their partisan electoral choices but retain their party identifications (partisan self-images) than they were to vary their party identifications (self-images) but maintain their partisan electoral preferences.

2. British voters were twice as likely as US voters to change both their party identifications (self-images) and their partisan electoral preferences across roughly the same electoral intervals.

Summing up these two specific findings, Butler and Stokes $(1969$, p. 43) stated that 'the British voter is less likely than the American to make a distinction between his current electoral choice and a more general partisan disposition'.

Butler and Stokes suggested that this Anglo-American difference in electoral behaviour was due to the difference between the system of balloting in the two countries. The British ballot for a national legislative election is very simple: it contains only the names (and parties) of the candidates for a single seat in the House of Commons; no other electoral choices are made at the same time. This contrasts sharply with the long ballot containing the name of candidates (and their parties) for a variety of national, state and local offices, as well possibly of referendum propositions, that is typically used in the United States. This difference in electoral mechanics, Butler and Stokes suggested, has given partisan 'dispositions' a more durable and commanding position relative to particular electoral choices in the United States than they enjoy within the British political context.

Without seeking to refute that argument, which appears plausible on its face value, we offer an alternate explanation for the cross-national differences in electoral behaviour that Butler and Stokes uncovered. The ordering of the questions in two of the three survey instruments employed by Butler and Stokes for their panel study may well have contributed towards blurring the essential distinction between party identification as a long-term personal attachment to a party, on the one hand, and a current partisan preference, on the other hand.

The procedure for eliciting the respondents' partisan identifications and electoral choices that is regularly employed in the US National Election Studies series includes asking first about party identification and later about current electoral preferences. That is the order followed when, as in off-years, there is only one postelectoral wave of interviews. When, as in the case of almost all presidential-year studies, there are both pre-electoral and post-electoral interviews, the two questions are even more sharply separated in that party identification is elicited at the preelectoral interview and partisan electoral choice is elicited at the post-electoral interview. The US data which Butler and Stokes used for their Anglo-American comparison rested on the pre- and post-electoral National Election Studies surveys for 1956 and 1960, and the single post-electoral survey for the off-year of 1958 .

The British data on which Butler and Stokes relied for their comparative analysis derived from one survey, conducted during the late spring and summer of 1963 , that was neither in the wake of a general election nor close to a forthcoming election, and two post-electoral surveys, one following the election of October 1964 and the other that of March 1966. The 1963 survey employed the question order 
typical of the US National Election Studies: partisan self-image was elicited prior to asking about the respondents' hypothetical vote intentions. In the two postelectoral studies of 1964 and 1966, however, the question order was reversed. In the 1964 survey, respondents were asked about their electoral choice at the 1964 election in Question 40d, while they were asked for their partisan self-image in Question 49a. In the 1966 instrument, the corresponding questions were Q.44c and Q.48a, rather more closely adjacent than they had been in the 1964 questionnaire."

The controlling assumption of this paper is that the two different question orders, the one routinely applied in the United States and used by Butler and Stokes in 1963, and the other employed by Butler and Stokes in 1964 and 1966, are not psychologically equivalent. The US ordering creates no urge in the respondents to be consistent in the two declarations of partisanship. The flow of meaning is from the general to the specific. This is a distinction with which everyone is familiar and which regularly produces contrasts that cause no psychological discomfort. People can like dogs generally but not like dobermans.

The opposite path, from the specific to the general, is less smooth. Once one has expressed a specific partisan choice, it would seem to be less than psychologically satisfying also to declare that one's more general partisan orientation is different. This would, we believe, be all the more true if the respondents were not given any indication that the question about partisan self-image was not meant to be considered within the context of a recent election but rather within the framework of a longer term, more general orientation towards the parties. The 1964 and 1966 British election studies, however, blurred that distinction. In those two studies, the question designed to elicit partisan self-image followed immediately upon a series of questions that referred specifically to the recent election.

We believe that in these circumstances, more British voters were subjected to the impulse to make their later declaration, relating to partisan self-image, consistent with their earlier report of their recent electoral choice, than US voters are to make their later report of their recent electoral choice consistent with their earlier expression of a long-term partisan attachment.

If this hypothesis is correct, the central Butler/Stokes finding that British voters make less of a distinction than US voters do between general partisan self-images and current partisan preferences is an artefact of their data-gathering technique in Britain and not something rooted in the country's pattern of political behaviour. And, if that is so, one can not only talk about 'party identification' in Britain with a clear conscience but also assume that there is less difference between British and US mass electoral behaviour than Butler and Stokes thought.

\section{The Structure of the Experiment}

In order to test our hypothesis that question order affects the degree to which British voters distinguish between long-term partisan dispositions and current partisan preferences, we mounted a split-sample panel study experiment. ${ }^{2}$ Specifically, we converted the 1983 British election study into the first wave of a three-wave panel study, whose second and third waves, conducted in 1986 and 1987 respectively, were randomly divided into two groups. One group was posed the questions relating to the vote and party identification in the order employed by Butler and Stokes in 1964 and 1966 (as well as in 1983); the question order was reversed for the second group, which was asked the two relevant questions in the order 
typically used in the United States and by Butler and Stokes for Britain in 1963.' We then subjected this data set to a series of tests, each of which was designed to discover whether the order of the questions affected the extent to which British voters distinguished between party identification and current partisan preference.

Before discussing those particular tests, it is important to comment on some of the properties of our three-wave panel.

1. The British party system of the 1980 s was more complex than that of the 1960s, when the Butler/Stokes surveys were conducted. The appearance of the Social Democratic Party and its alliance with the Liberals enlarged the party system so that it now included Liberals, Social Democrats and the Alliance in the space that had earlier been occupied only by the Liberals. The larger party system of the 1980 s relative to the 1960 s meant that one could expect less stability in both party identification and current partisan preferences in the later period than there had been in the earlier one (Heath et al., 1991, chap. 2).

2. We have measures of both party identification and the recent partisan vote for both 1983 and 1987. For 1986, however, while we have measures of PI, we have only the expression of partisan vote intention as the measure of current party preference. The original Butler/Stokes study was similarly unbalanced, although it was their first wave that lacked the declaration of an actual vote while it is our second wave that lacks it.

The asymmetry is more troublesome for us, however, than it was for Butler and Stokes, for two reasons. First, the lack of true vote report for the middle wave of our three-wave panel study means that we must bridge our widest temporal gap, from 1983 to 1987 , in order to match comparable declarations of current electoral preference. Because of the more compressed time span of the original Butler/Stokes panel, even if they had excluded their first wave, the remaining panel would still permit comparisons across only a two-year period.

The second reason compounds the difficulty created by the first. Our third panel wave naturally suffers both from attrition in numbers and a disproportionate loss of the politically uninvolved. Those properties alone, however, would not be particularly disturbing. The loss in case numbers is not decisive for any of our analyses. And we have weighted appropriately to restore the 1983 proportions of involved and uninvolved respondents among our third wave panel survivors. ${ }^{4}$ The major difficulty is that even after taking panel attrition into account, our third wave respondents, regardless of which of the two experimental groups they fall in, are much more politically involved than any of our cross-section samples, whether for 1983,1986 or 1987 . Between 1986 and 1987 , the proportion of uninvolved persons in our sample declined by almost 50 per cent.

That is a very large change, which can only be the result of response error. The only plausible source of the error that we can imagine is panel conditioning. Butler and Stokes $(1969$, p. 457) were alert to the possibility of such learning among the respondents of their own panel but did not detect any. The only reason we can think of why our sample should display such an effect so strikingly, compared with the Butler/Stokes nul finding, is that our third wave of interviews followed only one year after the second wave, while two years separated the Butler/Stokes second and third waves.

Whatever the explanation may be for the existence of the disproportionately large population of politically involved respondents among our third wave respondents, their presence badly biases our third wave sample. It is precisely the less 
politically involved persons who would be least likely to be sensitive to the subtle difference between current partisan preference and long-term party identification (if they do in fact register a party identification) and, consequently, most likely to confound the two. The sharp drop in numbers of such people at our third wave means that any differences between our two experimental groups in 1987 are likely to be highly attenuated.5

3. The 1983 survey was conducted before we designed our split-sample panel experiment, so it was not divided into two groups, and the relevant questions concerning party identification and current electoral preference were asked in what we hypothesize to be the 'wrong' order. The population of 1983 identifiers, therefore, contains some proportion of respondents whose declaration of party identification was, according to our hypothesis, merely the expression of a current partisan preference. Moreover, there is good reason to believe that this proportion was larger than usual in 1983. The instability in the British party system to which we already referred was particularly intense between 1979 and 1983, at least as measured in net aggregate terms. Assuming a four-party system [including the Conservatives, Labour, Liberals (and, from 1983 to 1987, the Social Democratic Party or the Alliance as well as the Liberals), and 'Other'l, aggregate net change in the proportions of the vote cast for each party between 1979 and 1983 was 23.2 per cent, compared with 6.4 per cent between 1983 and $1987,11.6$ per cent between 1959 and 1964, and 8.1 between 1964 and 1966. The potential for confusion between long-term party identification and current party preference would have been at its post-World War Two high in 1983. This means, of course, that we are faced with still another factor that would operate to attenuate any differences that we might find between our two experimental groups in 1986 or 1987, when those groups are linked for analytical purposes with our single 1983 sample.

When this potentiality for weak effects in the comparisons between 1983, on the one hand, and the two later years, on the other hand, is added to the reduction in variance that we expect to find in 1987 because of the disproportionately large number of involved voters among our 1987 panel survivors, it is apparent that we ought not to rely heavily on analyses that bridge 1983 and 1987. Accordingly, we include only one 1983-87 linkage among our discrete tests.

\section{Tests of the Hypothesis}

We performed five basic tests on our data set. Three were based only on crosssectional data. The other two tests exploited the panel properties of our data. Remember that the 1986 and 1987 panels were each divided into an A group and a B group. The A group was subjected to what we hypothesize to be the 'wrong' question ordering; the B group was queried according to the 'right' question ordering. Our experimental hypothesis is that the people in the B group will be less likely to equate party identification with current partisan preference than the people in group A will."

\section{Cross-sectional Analyses}

1. The Frequency of Party Identification. We would expect the proportion of reported party identifiers to be more numerous in Group A than in Group B. We would expect, further, that identifications with new parties, and references to questionable parties, would be more numerous in Group A than Group B. The 
TABLE 1. Frequency of party identification (1986)

\begin{tabular}{lrrrr}
\hline & Group A & Group B & \\
Conservative & 215 & & 206 & \\
Labour & 164 & & 164 & \\
Liberal & 70 & & 63 & \\
Scottish National & 9 & & 8 & \\
Plaid Cymru & 2 & & 2 & \\
& 460 & $83.8 \%$ & 443 & $82.5 \%$ \\
Social Democratic & 36 & & 35 & \\
Alliance & 3 & & 1 & \\
Greens & 2 & & 0 & \\
Other & 5 & & 0 & \\
& 46 & $8.4 \%$ & 36 & $6.7 \%$ \\
None & 28 & & 33 & \\
Don't know & 15 & & 25 & \\
& 43 & $7.8 \%$ & 58 & $10.8 \%$ \\
Totals & 549 & 100.0 & 536 & 100.0 \\
\hline
\end{tabular}

results of this test, for 1986, appear in Table 1 . The magnitude of the differences between the two groups is small, but the differences are in the right direction. $A$ larger proportion of Group A than of Group B reports identifying with a party, and the results for Group A contain a larger proportion of new parties and questionable cases than do those for Group B. The difference in the proportions of none/don't knows is statistically significant at the 0.05 level (using a one-tailed difference of proportions test).

2. The Strength of Party Identification by Age. Inasmuch as one expects strength of party identification to intensify with age, while there should be no relationship between age and strength of current party preference in the absence of a matching partisan identification (Converse and Pierce, 1985, pp. 154-6), the strength of PI within Group B should correlate with age more closely than it does within Group A. That is what we find. Again, for 1986, the difference is small, but in the right direction ( $r=0.28$ for Group B and 0.24 for Group A).?

3. Identity of Party Identification and Current Partisan Preference. Our third test, which in principle should have heen among the most simple and decisive, in fact turned out to be neither, although it raises issues of central importance in measuring different aspects of partisanship (see Converse and Pierce, 1985). If, as we hypothcsizc, the Group A respondents are more likely than those in Group B to confound current partisan preferences, with party identifications, those results should emerge clearly from simple cross-tabulations of those two variables, for each of our groups, as they were measured in 1986.

The problem, however, is that we do not have an unambiguous measure of current partisan preference for 1986 . The most reliable indicator of current preference is the report of how the respondents cast their votes at a recent election, but of course there was no general election in 1986. Another measure of current voting preference is the frequently used question: 'Which party would you vote for if there were a general election tomorrow?' 8 The relevant measure in the 1986 survey was of a different kind. The respondents were first asked if they had decided how they 
would vote in the next election, and then, if they replied that they had, they were asked for which party they had decided to vote. That is certainly a measure of partisan preference, but while it might only reflect the current preferences of some respondents, it might rest on general, longer-term partisan attachments for others.

In these circumstances, what should the experimental hypothesis actually be? If our vote intention measure reflects current partisan preferences, we would expect the overlap between them and party identification to be greater for Group $A$ than for Group B. If the measure reflects long-standing partisan dispositions, the overlap should be greater for Group B than for Group A! In point of fact, the overlap is virtually identical for the two groups, which is perhaps not surprising, given the inherent ambiguity of our measure of partisan preference for 1986.

\section{Panel Analyses}

4. The Stability of Party Identification. The longitudinal stability of true party identifications should be greater than that of an admixture of true and false party identifications. We tested this proposition three ways.

First, we simply cross-tabulated (for each of our two experimental groups) Party Identification in 1983 with Party Identification in 1986, among people who registered a party identification at both waves. The result, which appears in Table 2(a), moderately supports our basic hypothesis that Group B will contain a larger proportion of true identifiers than Group A does.

We have already remarked, however, that our 1983 identifiers were determined on the basis of what we hypothesize to be a faulty question ordering and, therefore, must be assumed to contain false as well as true identifiers. In order to try to remove the false identifiers from the 1983 sample, we reduced the panel set to include only those reported 1983 identifiers whose PI was not the same as their

TABLE 2. Stability of party identification (1986)

(a) Among respondents with a party identification in both 1983 and 1986

$\begin{array}{lcc} & \text { Group A } & \text { Group B } \\ \text { Same PI } & \% & \% \\ \text { Different PI } & 80.5 & 83.5 \\ & 19.5 & 16.5 \\ & 100.0 & 100.0 \\ & (\bar{N} 442) & (\mathrm{N} 413)\end{array}$

(b) Among respondents whose 1983 party identification did not match their 1983 electoral preference

Same PI

\begin{tabular}{cc} 
Group $A$ & Group $B$ \\
$\%$ & $\%$ \\
36.7 & 47.1 \\
53.1 & 39.1 \\
8.2 & 6.8 \\
2.0 & 7.0 \\
\hline 100.0 & 100.0 \\
$(\mathrm{~N} 49)$ & $(\mathrm{N} 41)$ \\
\hline
\end{tabular}

Different PI

No PI in 1986

Don't know PI in 1986 
vote. These respondents, by definition, cannot include anyone who equated a current electoral preference with a party identification. Then, in a second analysis, we re-ran the same cross tabulation, for each of our two experimental groups, between PI in 1983 and PI in 1986, that we first ran for the entire 1983 panel set.

The results of this second analysis appear in Table 2(b). Case numbers are, of course, sharply reduced, but this time the difference between Groups A and B, which is still in the proper direction, is more decisive. Even taking into account cases of no PI and Don't Knows in 1986, a distinctly larger proportion of people in Group B than in Group A retained the same PI. If one reduces the set further to include only persons who registered a PI at both waves (as we did in our first longitudinal analysis), case numbers shrink still further, but the difference between the two groups widens, and in the predicted direction.?

5. Joint Turnover of Party Identification and Electoral Preference. The Butler/Stokes proposition about the greater likelihood of British voters than US ones to equate current electoral preferences with partisan self-images rested on two nowfamous joint turnover tables that have been reproduced in various guises since Butler and Stokes (1969, pp. 41-42) first presented them (Cain and Ferejohn, 1981; Converse and Pierce, 1986, p. 88; LeDuc, 1981). These tables, which took the form presented in Fig. 1, included only those British and US respondents who professed both a party identification and an electoral preference at each of three waves of panel surveys. The analysis compared the proportions of voters in each country whose partisan self-image and whose voting preference remained constant or changed across the 1963-1964-1966 panel period for Britain and the 1956-1958-1960 panel period for the United States. The Butler/Stokes proposition that we are testing here derived from two elements of the comparison. First, the ratio of cell $b$ to cell $c$ was some eight times larger for the United States than for Britain, signifying a much greater tendency for US voters than for British ones to change their vote without changing their party identifications. Second, the magnitude of cell $d$ was twice as large proportionately for Britain as for the United States. This indicated a much greater propensity in Britain than in the United States for voters to change both their party identification and their current clcctoral preference within the panel time frame.

For the final test of our series, we tried as nearly as possible to replicate the Butler/Stokes joint turnover tables for each of our two experimental groups. The match could not, of course, be very close, for reasons that we have touched on along the way. The original Butler/Stokes comparison between Britain and the

\begin{tabular}{lcccc}
\hline \multicolumn{4}{c}{ Voting preference } \\
& Stable & Stable & Variable \\
Partisan & & & $b$ \\
Self-image & & & & \\
& Variable & $c$ & $d$ & $a+b+c+d-100 \%$ \\
\hline
\end{tabular}

Fig. 1. The Butler-Stokes joint turnover table. Source: D. Butler and D. Stokes, Political Change in Britain: Forces Shaping Electoral Choice, (New York: St. Martin's Press, 1969). 


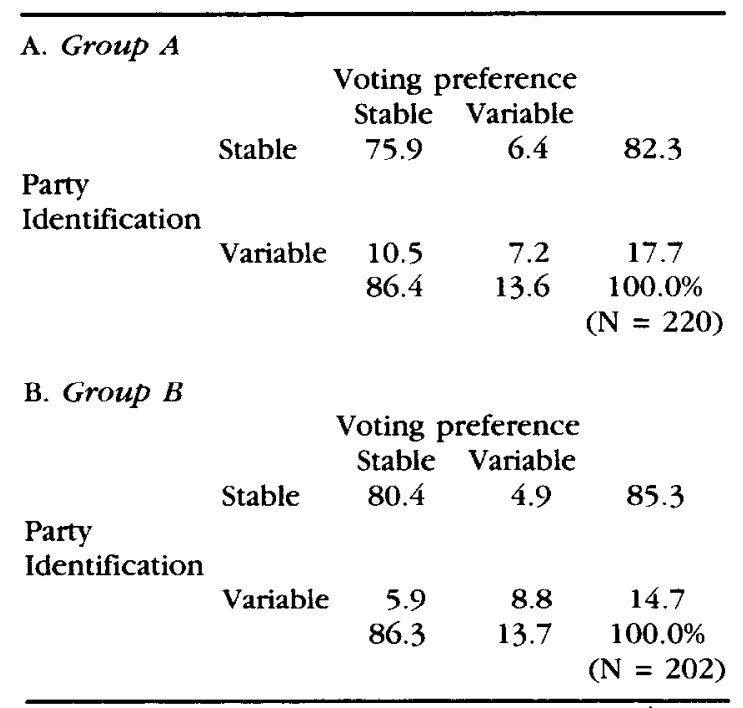

FIG. 2. Joint turnover of party identification and electoral preference (Great Britain, 1983-86-87).

United States covered different time spans and did not rest on wholly identical variables, so no single replication of our own could possibly match both terms of theirs. But even limiting ourselves to the British side, there are differences that cannot be overcome. The Butler/Stokes panel span was three years while ours is four years. Butler and Stokes had reports of 'true' votes for their second and third waves; we had them for our first and third waves. Only two years separated their true vote reports while four years separated ours. Yet the logic of our investigation compels us to come as close as we can to replicating the analyses from which the problem under investigation originated.

The results appear in Fig 2. Part (A) of Fig. 2 reports the results for our Group A, which was subjected to the 'wrong' question order in 1983, 1986 and 1987, while Part (B) presents the results for the respondents in Group B, who were questioned about their partisanship in the 'right' order in 1986 and 1987 (but not in 1983). Our interest lies, of course, in comparing Group A with Group B, with a view to discovering whether there are differences between them similar to the differences that Butler and Stokes uncovered between Britain and the United States. Our hypothesis is that our Group A will more closely resemble the Butler/Stokes findings for Britain, while our Group B more nearly match the Butler/Stokes table for the United States.

The results do not support the hypothesis. The two dynamic properties that Butler and Stokes found to differ between the United States and Britain during the late 1950s and 1960s are not mirrored in corresponding differences between our two experimental groups. The ratio of cell $b$ to cell $c$ differs only slightly from one table to the other, and the proportion of respondents occupying cell $d$ is very similar in the two tables. Fig. 2(A) does not resemble the Butler and Stokes turnover table for Britain in the 1960s; Fig. 2(B) does not look like their corresponding table for the United States. On the basis of this test, we cannot say that the respondents in Group A display more of a tendency than those in Group B to equate party identification with current electoral preference. 
Of course, we had reason from the start for believing that when we crosstabulated the results for the 1983 sample (with its admixture of presumed true and false identifiers) with our 1987 sample (which included a disproportionately small number of uninvolved citizens), passing through our 1986 sample (for which we had only declarations of future vote intention and not true expressions of electoral preference), any differences between our two experimental groups would be highly attenuated.

We do not, however, want to press that argument too far. Despite the factors moving our two groups towards convergence, Fig. 2 reveals two important differences between groups $A$ and $B$ that suggest that question order does indeed affect the reliability of professions of party identification.

First, party identification across the entire panel span was greater for Group B than for Group A. As in the cases of several of our other tests, the magnitude of the difference is small-a matter of only three percentage points-but the difference is in the right direction. True party identifications should be more stable than admixtures of true party identifications and current party preferences.

The second difference, which is related to the first, is that almost twice as many people from Group A as from Group B, proportionately, were stable in their expressions of electoral preference but unstable in their declarations of party identification. (This difference was significant at the 0.05 level using a one-tailed difference of proportions test.) We would normally not expect a large proportion of respondents to fall in cell $c$; in the original Butler and Stokes tables, only 4 per cent of British voters and 2 per cent of US voters did so.

There are, however, two factors than can plausibly account for the increased proportions of people populating the $c$ cells of Fig. 2. One is methodological, while the other is purely political, although both are related to the greater fragmentation of the British party system during the 1980s as compared with the 1960s. Because there was only one Alliance candidate in any constituency in 1983 and 1987, and that candidate could be either a Liberal or a Social Democrat, we have counted all three of those labels as equivalent in our analysis of voting preference. Thus a voter who switched from voting Liberal to voting Social Democrat, or the reverse, counts as stable in our calculations. Party identifications, however, are necessarily discrete. Therefore, a voter whose party identification changed from Liberal to Social Democrat, or the reverse, counts as variable. There were no comparable complexities during the $1960 \mathrm{~s}$.

But even apart from the possible effects of our handling of Alliance candidates for analytical purposes, there were political reasons why more Conservative or Labour identifiers than usual might be led to change their party identification but not their vote (I've always been a Conservative, but I can't stand that woman, I've always been for Labour, but this isn't the party I've known).

There are, therefore, good reasons why there should be a larger proportion of persons in the $c$ cells of the two tables of Fig. 2, that represent Britain in the unstable 1980s, than there were in the original Butler and Stokes table reflecting the more placid 1960s. The fact remains, however, that nearly twice as many people from Group A as from Group B, proportionately, reported stable voting preferences but variable party identifications.

We can think of no reason for the phenomenon other than that the respondents in Group A were more confused than those in Group B about the meaning of the question they were asked concerning their general feelings of partisan attachment, 
so soon after they had already declared their partisan preferences. Some people in Group A may have been impelled by the question order to make a profession of partisanship consistent with their prior declaration of electoral preference at one or two interview waves but not at all of them. We have already suggested, in connection with our third test, that the impulse toward consistency may be weaker when statements of vote intention, as opposed to actual vote reports, are involved.

In this, our fifth and final test, we have not shown that 'wrong' question order induces respondents to bring their professions of party identification into line with their earlier declarations of current electoral preference. We have, however, uncovered clear indications that wrong question order can produce a higher than normal level of response uncertainty.

\section{Discussion}

We have conducted five different types of tests in the effort to determine whether question order may have accounted for the greater tendency of British voters than of US ones to equate current party preference with party identification that was reported by Butler and Stokes $(1969$, p. 43) almost a quarter of a century ago. The problem remains of how to evaluate the results. We could, of course, simply add up the number of times our hypothesis was not rejected and how many times it was. That would be incomplete and misleading, however, without also referring to the specific findings of each test and the particular properties of the data used for each test.

Our first two tests, which rested on clean measures of party identification that differed only in their order in the questionnaires relative to questions about current electoral preference, indicated modestly but unambiguously that more 'true' identifiers are uncovered when the question about party identification precedes the question about current electoral preference than when it follows it.

Our third test was designed to be a direct test of the hypothesis that more respondents equate party identification with current party preference when the former is elicited after, rather than before, the latter. The test failed, but it was also an uncertain test, in that it rested in part on a measure of future vote intention as opposed to a measure of recent partisan choice. The negative outcome, therefore, must be held in abeyance, until such time as a more proper test can be mounted.

Our fourth test differed from the first three in that it included a dynamic component, which is particularly appropriate given that the elements of electoral theory that surround the concept of party identification are important especially for their dynamic implications. We performed two variations of this dynamic test, and each of them sustained our hypothesis. Moreover, these variants of the fourth test, like our first two, simpler tests, were clean in the designation of the sets of respondents and consistent in the measures employed. As a result, we place particular emphasis on the result of this fourth test.

Finally, our fifth and most ambitious test, which in principle ought to have been the centrepiece of our analysis, was almost hopelessly flawed by measurement mismatches beyond our control. Like our third test, this one was designed to tackle head-on, and in an even more complex dynamic framework, the issue of why Britons more so than Americans had seemed to Butler and Stokes to equate party identification with current party preference. We found no direct support in the data for our hypothesis that question order is responsible for that particular 
phenomenon. We did, however, find evidence that what we hypothesize to be inappropriate question order can produce confusion in the minds of the respondents about what they are being asked, with the result that people report party identifications that are not in fact true.

Taking all of these results and qualifications into account, it would appear that we have not been able to show beyond reasonable doubt that improper question order causes respondents to equate party identification with current electoral preference, but we have been able to support the propositions that:

1. Proper question order elicits a larger proportion of true party identifiers than improper question order does; and

2. Improper question order produces response uncertainty in the reporting of party identification.

Students of British electoral behaviour would do well to mount a new and purer split-sample survey experiment than we are able to do, in order to put this question to rest once and for all. In the meantime, we suggest that they resist the temptation to distinguish between what Butler and Stokes referred to as partisan self-image and what others call party identification. Britons and Americans are almost surely not as different in their electoral behaviour as Butler and Stokes thought they were.

\section{Notes}

1. This same question order, with the question concerning the vote preceding the question concerning party identification, was retained in all succeeding British electoral studies in the same series through 1987.

2. The data come from the 1983-6-7 British Election Panel Study. Respondents for the panel study were taken from the 1983 British Election Survey, a stratified nationally-representative probability sample of the electorate, drawn from 250 parliamentary constituencies, and interviewed in the weeks following the 1983 general election. 3955 respondents were interviewed in this survey, a response rate of 72.4 per cent. (For further details see Heath, Jowell and Curtice, 1985.) For cost reasons, it was decided not to follow up all the respondents to the 1983 survey. Respondents in 115 of the original 250 constituencies were chosen (the 115 constituencies being selected on a systematic random basis within the strata used for drawing the original 250). At the end of the 1983 survey, respondents were asked whether they were willing to be re-interviewed. After deletion of those unwilling to be re-interviewed, 1634 respondents' names and addresses were issued to interviewers. One round of interviews took place in November/December 1986, and a total of 1090 productive interviews were achieved. For the final round of interviews, which were undertaken immediately after the 1987 general election, 1020 names and addresses were issued to interviewers (the remaining 70 having said in 1986 that they were unwilling to be re-interviewed). 869 productive interviews were achieved. For details of the components of non-response see Farrant and O'Muircheartaigh (1991).

3. The exact question numbers for the three surveys are as follows. 1983: Q.9A (Party Vote); Q.13A (Party Identification). 1986: Group A. Q.3B (Vote Intention); Q.7A (Party Identification). Group B. Q.3A (Party Identification); Q.7B (Vote Intention). 1987: Group A. Q.5A (Party Vote); Q.10A (Party Identification). Group B. Q.3A (Party Identification); Q.31A (Party Vote).

4. Butler and Stokes (1969, pp. 454-8) weighted their third wave responses jointly on three variables, the most important of which referred to political information, an item that is closely related to political involvement.

5. 'Tis a pity for several reasons. The $B$ group of 1987 has the question order configuration that most closely approximates the one used in the United States, as the two relevant questions are spaced widely apart (see n.3).

6. The distributions of party identification and strength of party identification within Group A in 1983 differed somewhat from those within Group B. In order to standardize the two 
groups on those variables, we computed a weight that, when applied to Group B, produced the same distributions on the two variables that pertained to Group A. When our analysis included 1987 respondents, this weight was combined with the weight designed to compensate for the loss by attrition of a disproportionate number of uninvolved persons.

7. For 1987 , when there is virtually no difference in the frequency of party identification between Groups A and B, the difference in the correlation between strength of PI and age is also larger for Group B $(r=0.18)$ than for Group A $(r=0.13)$.

8 . It is by no means certain that this question would be interchangeable with a recent vote report for our purposes. Respondents might feel less of an impulse to make a declaration of party identification consistent with a prior expression of a vote intention (which implies no commitment) than with an earlier report of a recent electoral choice (which describes a decision).

9. For all cross-tabulations involving party identification declarations exclusively, we have treated the Liberals, the Social Democratic Party, and the Alliance as separate parties and not interchangeable.

\section{References}

D. Butler and D. Stokes, Political Change in Britain: Forces Shaping Electoral Choice, (New York: St Martin's, 1969).

B.E. Cain and J. Ferejohn, 'Party Identification in the United States and Great Britain', Comparative Political Studies, 14: 1981, pp. 31-48.

P.E. Converse and R. Pierce, 'Measuring Partisanship', Political Metbodology, 11: 1985, pp. 143-66.

P.E. Converse and R. Pierce, Political Representation in France, (Cambridge, Mass: Harvard, 1986).

G. Farrant and C. O'Muircheartaigh, 'Components of nonresponse bias in the British Election Surveys' in A.F. Heath et al. Understanding Political Change: The British Voter 1964-1987, (Oxford: Pergamon, 1991).

A.F. Heath, R.M. Jowell and J.K. Curtice, How Britain Votes, (Oxford: Pergamon, 1985).

A.F. Heath, R.M. Jowell, J. K. Curtice, G. Evans, J. Field and S. Witherspoon, Understanding Political Change: The British Voter 1964-1987, (Oxford: Pergamon, 1991).

L. LeDuc, 'The Dynamic Properties of Party Identification: A Four-Nation Comparison', European Journal of Political Research, 9: 1981, pp. 257-68. 